Working

Paper

Department

of Economics

$\mathrm{Ca}^{\prime}$ Foscari University of

Venice

Barbara Buchner

Carlo Carraro

Economics and

environmental effectiveness

of a technology-based

climate protocol 


\title{
Economic and Environmental Effectiveness of a Technology-based Climate Protocol
}

\author{
Barbara Buchner \\ Fondazione Eni Enrico Mattei \\ Carlo Carraro \\ University of Venice, Fondazione Eni Enrico Mattei, CEPR, CESifo and CEPS
}

\begin{abstract}
The present stalemate in climate negotiations between the US and the other Annex I countries has led policy analysts and economists to explore the possible emergence of alternative climate regimes that may be applied after 2012. This paper explores the idea of replacing international cooperation on greenhouse gas emission control with international cooperation on climate-related technological innovation and diffusion. This idea - recently proposed among others by Barrett (2001) and Benedick (2001) - is based on the insight that incentives to free ride are much smaller in the case of technological cooperation than in the case of cooperation on emission control. This paper provides a first applied game theory analysis of a technology-based climate protocol by assessing: (i) the selfenforcingness (namely, the absence of incentives to free ride) of the coalition that would form when countries negotiate on climate-related technological cooperation; (ii) the environmental effectiveness of a technology-based climate protocol. The analysis is carried out by using a model in which endogenous and induced technical change are explicitly modelled. The results of our analysis partly support Barrett's and Benedick's conjecture. On the one hand, a self-enforcing agreement is more likely to emerge when countries cooperate on environmental technological innovation and diffusion than when they cooperate on emission abatement. However, technological cooperation - without any commitment to emission control - may not lead to a sufficient abatement of greenhouse gas concentrations.
\end{abstract}

\section{Keywords}

Agreements, Climate, Incentives, Technological Change, Policy

JEL Codes

C7, H0, H4, O3

Address for correspondence:

Carlo Carraro

Department of Economics

Ca' Foscari University of Venice Cannaregio 873, Fondamenta S.Giobbe 30121 Venezia - Italy

Phone: (++39) 0412349166 Fax: (++39) 0412349176 e-mail: ccarraro@unive.it

This Working Paper (o QD se in inglese) is published under the auspices of the Department of Economics of the Ca' Foscari University of Venice. Opinions expressed herein are those of the authors and not those of the Department. The Working Paper series (o QD se in inglese) is designed to divulge preliminary or incomplete work, circulated to favour discussion and comments. Citation of this paper should consider its provisional character

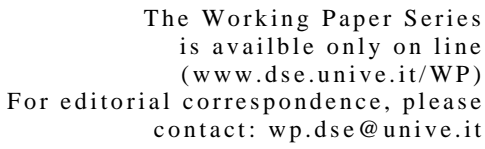

The Working Paper Series is availble only on line (www.dse.unive.it/WP)

For editorial correspondence, please contact:wp.dse@unive.it

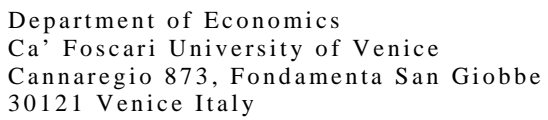




\section{Introduction}

Climate change control is a global governance problem. Any strategy to control climate change will only be effective if adopted by as many countries as possible, or at least by a number of countries which account for a large share of total emissions. However, due to the absence of a supranational authority that can enforce environmental policies and regulations on a global scale, climate change control can only be achieved via voluntary initiatives and international agreements among sovereign countries. ${ }^{1}$

In the context of climate change, the Kyoto Protocol was welcomed as an important achievement in international diplomacy, because, for the first time, it succeeded in establishing binding emissions reduction targets for industrialised countries. However, the US decision not to ratify the Protocol has largely reduced its environmental effectiveness, thus inducing all countries to adapt their own climate strategy to a new scenario in which some major current and potential future greenhouse gas emitters do not cooperate on emission control.

Even though Russia's decision to ratify the Protocol made the Protocol to enter into force on February 16, 2005, its environmental effectiveness is widely recognised as very limited. Therefore, a number of alternative proposals designed to increase the environmental effectiveness of an international climate agreement have emerged. ${ }^{2}$ The environmental effectiveness of a climate agreement can be enhanced through two main steps: (i) by increasing the number of signatory countries, and (ii) by making abatement targets more stringent. As a consequence, new recent proposals on climate change policy address both the issue of participation incentives and the issue of long-run costs of effective abatement targets.

\footnotetext{
${ }^{1}$ This basic point identifies the boundaries of most analyses of international negotiations on climate change. See Barrett (2002) for a survey.
} 
Among recent proposals on climate policy, there is the idea - supported among others by Barrett (2001) and Benedick (2001) - to replace international cooperation on greenhouse gas emission control with international cooperation on climate-related technological innovation and diffusion.

This idea is based both on theoretical arguments and on empirical facts. First, theory suggests that incentives to free-ride are much smaller in the case of technological cooperation than in the case of cooperation on emission control (Cf. Carraro and Siniscalco, 1995, 1997; Yi, 1997). Therefore, a technology-based climate protocol could be self-enforcing, i.e. it could be signed by all or almost all countries worldwide. Second, in recent years countries have begun to adopt domestic policy measures and to sign bilateral and multilateral deals to enhance investments in $R \& D$ and the diffusion of climate-related technologies (see Section 2 below for an overview). This seems to confirm that agreements on environmental technological cooperation are easier to sign and implement than agreements on emission abatement.

However, albeit self-enforcing - a property which is unlikely to be shared by climate regimes where cooperation concerns emission control - a technology-based climate regime may not be environmentally effective. The reason for this is that while, on the one hand, cooperation on climate-related technological innovation and diffusion reduces emissions per unit of output, abatement costs and therefore global GHG emissions, on the other hand, investments in $\mathrm{R} \& \mathrm{D}$, as well as the adoption of new technologies and new standards, stimulate economic growth both in developed and developing countries, thus increasing global emissions. The outcome of these two combined effects cannot easily be assessed using only a theoretical framework. A quantitative analysis becomes necessary in order to verify 
whether the adoption of a technology-based climate regime actually reduces GHG emissions. This is the key objective of this paper.

Using the FEEM RICE model - a modified version of Nordhaus and Yang's (1996) and Nordhaus and Boyer's (2000) RICE model - we will make an initial assessment of the environmental and economic benefits of a technology-based protocol, and in particular of whether the total amount of global emissions is actually reduced by the adoption of an international agreement in which all countries find it profitable to cooperate on technological innovation and diffusion. In order to test the robustness of the analysis we will use two different models with different specifications of how technical change evolves over time. In addition, sensitivity analysis on the key parameters of the models will be carried out.

We proceed as follows. In section 2, we present an overview of recent climate initiatives and developments in climate policy. Section 3 describes some policy proposals designed to overcome some of the shortcomings of the Kyoto Protocol. In particular, we present the main features of Barrett's (2001, 2002) and Benedick’s (2001) proposal. In section 4, we use the FEEM RICE model to examine whether a technology-based climate regime would actually yield economic benefits and increase environmental effectiveness. The final section draws some policy conclusions.

\section{Climate negotiations and bilateral technological agreements}

In spite of the US decision to withdraw from the Kyoto Protocol, several climate initiatives have been developed both within and outside the Kyoto policy framework. On the one hand, in several Annex B countries measures to achieve the Kyoto targets have been adopted (e.g. the EU Directive on emission trading or the Japanese climate plan). On the other hand, the US has implemented a domestic climate policy designed to achieve a $-18 \%$ 
reduction in energy intensity. ${ }^{2}$ Most importantly from the point of view of this paper, in recent years a large number of bilateral agreements on technology and scientific cooperation have been signed between various countries throughout the world.

For example, the European Union cooperates on international scientific policy with almost 30 countries $^{3}$ and the US is engaged in a large number of joint technology projects as well. ${ }^{4}$ In particular, a variety of proposals on technology development projects have emerged in the context of climate change control.

At COP 9 in Milan, the US Department of Energy presented two new reports from the US Climate Change Technology Program, stressing the three pillars of the US strategy on climate change: science, technology and international cooperation. The reports discuss a portfolio of federal R\&D investments in climate change technology development and emphasise that research into innovative technologies - such as hydrogen, bio-energy, carbon sequestration - will address the issue of climate change by devising “a path to stabilising atmospheric GHG concentrations” and ensuring

\footnotetext{
${ }^{2}$ The plan - announced in February 2002 and presented in greater detail at COP 9 in Milan - to lower the US greenhouse gas intensity by $-18 \%$ over the next 10 years in order to slow the growth of GHG emissions per unit of economic activity is analysed in De Moor et al. (2002), Goulder (2002), Viguier (2002). Although President Bush’s Climate Change Initiative implies a very modest US emissions reduction target, it represents at the same time an acknowledgement of the long-term character of the climate change problem and thus improves the prospects for a US participation in international efforts to combat climate change (White House, 2002).

${ }^{3}$ In particular, the EU has signed science and technology cooperation agreements with Argentina, Australia, Brazil, Canada, Chile, China, India, Japan, Russian Federation, South Africa, Tunisia, Ukraine, United States, a S\&T agreement with New Zealand and has formed RTD associations with Bulgaria, Cyprus, Czech Republic, Estonia, Hungary, Iceland, Latvia, Lithuania, Malta, Norway, Poland, Romania, Slovakia, Slovenia and Turkey. For further information see http://europa.eu.int/comm/research/iscp/countries.html

${ }^{4}$ Currently, the US has signed agreements for scientific and technological cooperation with 34 countries and the European Union. For further information on the activities of the Office of Science and Technology Cooperation established by the US Department of State see http://www.state.gov/g/oes/stc/.
} 
"secure, affordable, and clean energy to power economic growth worldwide". 5

These research activities are to be undertaken both domestically and in cooperation with other countries, as is already demonstrated by the various bilateral climate technology agreements signed between the US and other nations. For example, the "US-Australia Climate Action Partnership" is an initiative consisting of various programs aimed at improving the scientific cooperation in areas including climate change science, reduced emissions strategies and engagement with business on technology to reduce GHG emissions (News.com.au, July $2^{\text {nd }}, 2002$, CO2e.com, July $7^{\text {th }}, 2002$ ). A similar partnership exists between the US and Japan and aims at promoting joint projects and exchanging opinions on various measures to prevent global warming (CO2e.com, April $5^{\text {th }}, 2002$ ). On the same basis, agreements for technology cooperation have been signed between the US and Russia (Pravda, Jan. 17 ${ }^{\text {th }}$, 2003), as well as between the US and Italy, India and China.

The European Union is also engaged in a number of technology agreements aimed at the improvement of energy technologies and more generally at the development of climate friendly production processes. For example, an agreement with China on strengthened environmental technological cooperation has been signed ${ }^{6}$, while the single EU Member States are collaborating in numerous bilateral projects. ${ }^{7}$

\footnotetext{
${ }^{5}$ For more information on the US Climate Change Technology Program and its reports see http://www.climatetechnology.gov/.

6 For more information on the EU-China agreement see http://www.delchn.cec.eu.int/en/whatsnew/ Pren121103.doc.

${ }^{7}$ See for example http://www.mex.dk/uk/vis_nyhed_uk.asp?id=5834\&nyhedsbrev_id=824 for information on a bilateral climate agreement between Denmark and Bulgaria or http://www.climate.org.ua/whatdone/intrn.html for details on the bilateral agreements established with the Ukraine.
} 
Japan has parallel initiatives with the US and is at the same time strengthening its role in climate cooperation within Asia. In August 2002, the Japanese government announced plans to help other Asian countries reduce greenhouse gases (Jiji Press, Aug. $1^{\text {st }}$, 2002) and the start of a joint research initiative with seven developing Asian nations aimed at providing technological assistance to the other countries to reduce their GHGs in exchange for CO2 emissions credit (The Daily Yomiuri, Aug. $26^{\text {th }}$, 2002). In addition, Japan also acts by exporting pollution control technologies and implementing (since 1992) a "Green Aid Plan” to develop research and provide technological assistance for environmental-friendly projects throughout Asia (EIA, 2003).

There is therefore an increasing focus on technology as the main way to address the climate change problem, particularly in the long-run. And it is also clear that international cooperation can help develop and disseminate climate-friendly technologies. The recent success in establishing bilateral and multilateral international agreements on technological cooperation may suggest that Barrett's (2001, 2002) and Benedick’s (2001) proposal to adopt a technology-based climate protocol might be a better way to address climate change than a protocol in which countries must agree on voluntary GHG emission reductions. However, the recent initiatives briefly outlined in this section are merely indicators of a possible evolution of climate policy, but do not yet support any conclusions in favour of a technology-based climate protocol. This is why we plan to address this issue in this paper and to provide an assessment of this policy proposal, which will be described in greater detail in the next section.

\section{A climate policy regime based on technological cooperation}

Despite the fact that the Kyoto Protocol eventually entered into force on February 2005, its low environmental effectiveness and the absence of some major present and/or future emitters (e.g. US, China, India, Brasil) from the set of signatory countries, has led several analysts to explore the possible 
expediency of other climate regimes. A first option is a climate regime in which the US adopt their own climate policy - possibly in cooperation with some developing countries - whereas the other Annex B countries remain committed to the Kyoto Protocol (Cf. Buchner and Carraro, 2003). A second option is a climate regime in which the Kyoto Protocol is integrated with measures and policies to induce the US to modify their present decision and to ratify the modified Protocol $^{8}$. A third possible regime is based on a completely different approach, in which all countries are required to agree on a climate strategy which is no longer based on the cap and trade of emissions. This new climate regime could be based, for example, on an international carbon tax (Nordhaus, 2001) or on a set of harmonised domestic carbon taxes (Cooper, 1998) or on the adoption of different domestic measures to curb GHG emissions (e.g. in the case of the Global Climate Marshall Fund proposed by Schelling, 2002). ${ }^{9}$

Less radical proposals suggest enhancing the incentives for participation and compliance by focusing on some weaknesses in the Kyoto architecture. For example, some of these proposals investigate a combination of relatively modest short-term goals with more stringent long-term targets, in order to lower the initial burden to commit to the climate agreement. These proposals often include near-term commitments for developing countries ${ }^{10}$. Other proposals aim at reducing the expected costs of the Kyoto Protocol by introducing hybrid policy instruments, e.g. the combination of a quantity instrument (such as emissions trading) with a price instrument (such as a tax

${ }^{8}$ One solution often proposed in the literature on international regimes is to link cooperation on climate change control (typically a public good) with cooperation on a club or quasi-club good. This strategy has recently been explored by Tol, Wise and van der Zwaan (2000), and Buchner, Carraro, Cersosimo and Marchiori (2002) which focus on the linkage of climate cooperation with technological cooperation.

${ }^{9}$ For a discussion of different proposals see for example Aldy et al. (2003), Aldy, Barrett and Stavins (2003), Baumert et al (2002), Barrett and Stavins (2004), CNRS/LEPII-EPE et al. (2003) and OECD/IEA (2002).

${ }^{10}$ See for example, Barrett (2001 and 2002); McKibbin and Wilcoxen (1997); McKibbin (2000) and Schmalensee (1998). 
or safety valve) ${ }^{11}$. Other proposals suggest adopting a step-by-step approach to climate policy by focusing first on regional agreements (regional "bubbles" to be developed within the Kyoto Protocol) and then moving on to a global agreement ${ }^{12}$.

More radical proposals are based on the observation, largely shared by climate scientists, that without a real technological breakthrough it will be very difficult to achieve the stabilisation of GHG concentrations. ${ }^{13}$ Therefore, an effective climate regime should be based on measures that enhance climate-friendly technological innovation and dissemination and reduce the future costs of greenhouse gas abatement.

The idea that technological cooperation is the appropriate tool to deal with the problem of global warming is not only the basis of the Bush administration's climate policy, but has also been proposed as the framework of a new approach to climate policy at international level by Barrett (2001, 2002) and Benedick (2001). They argue that an international agreement for the development and diffusion of technologies designed to reduce GHG emissions could be a possible approach that countries may decide to adopt to combat climate change ${ }^{14}$.

\footnotetext{
${ }^{11}$ See for example, Kopp, Morgenstern, Pizer and Toman (1999); McKibbin and Wilcoxen (1997); McKibbin (2000); and Victor (2001)

12 See Buchner and Carraro (2004).

${ }^{13}$ This is largely true for motor vehicles and aircrafts, since technologies for reducing GHG emissions in these areas are not yet available. Instead, in energy generation and demand, there already exist suitable technologies for electricity generation at low carbon and energy efficiency measures at various stages of development. Indeed, given that these technologies and measures could significantly reduce GHG emissions if adopted on a large scale, the main problem in this context is one of bringing the available technologies to market, not one of fundamental technological breakthroughs.

${ }^{14}$ See for example Barrett (2001 and 2002), Benedick (2001), Edmonds, Roop and Scott (2000), Edmonds (2001), Flannery (2001), Jacoby (1998). The relative performance of technological innovation with respect to environmental policy tools is discussed in Parry, Pizer and Fischer (2002).
} 
As discussed in section 2, the idea of a technology-based climate protocol is not based on a vacuum. The proliferation of bilateral agreements on technology cooperation - and on climate technology cooperation in particular - would seem to indicate that the proposal for a technology-based climate protocol is worth serious consideration. This type of protocol could be established within the UNFCCC and could be a complement, if not a substitute, of the Kyoto Protocol.

Let us provide a more detailed description of this idea. Barrett $(2001,2002)$ and Benedick (2001) propose a technology-based international strategy to tackle the incentives to free-ride which usually undermine the possibility of cooperation on emission control. In particular, Barrett (2001, 2002) argues that the Kyoto Protocol provides poor incentives for participation and compliance and tries to solve this problem by suggesting an alternative climate regime, which is based on common incentives for the development and adoption of climate-friendly technologies.

The main elements of this proposal include cooperative funding of basic R\&D into energy-saving, climate-friendly technologies on the one hand, and the implementation of various standards directed towards the world-wide adoption and diffusion of new technologies on the other. Common standards for technologies are identified through collaborative research efforts ${ }^{15}$, which are financed through the global R\&D fund. Every country should be given the option to sign both the standards protocol and the cooperative $R \& D$ protocol. Since standards are a public good, no country can be excluded from using them. By imposing an open standards protocol, Barrett accounts for competition which induces pull incentives. In addition, the standards protocol is intended to be non-exclusionary in order to encourage the widespread adoption and diffusion of new technologies.

\footnotetext{
${ }^{15}$ Barrett (2001) cites the example of energy efficiency standards for cars, which could be established requiring e.g. the use of new hybrid engines or fuel cells.
} 
However, to construct a global climate regime which is accepted by all countries, an element of fairness needs to be incorporated, taking into account that the current accumulation of GHG emissions in the atmosphere is basically caused by the industrialised countries. In order to provide incentives for the developing countries to adopt the new standards which will require costly technologies, Barrett suggests making the share of each country's contribution to collaborative funding dependent on its circumstances $^{16}$. In this way, the need for the developing countries to grow is satisfied but - acknowledging that they will probably be the biggest future emitters - they nevertheless take part in a climate regime. In addition, taking the Montreal Protocol as an example, the industrialised countries are made responsible for the financing of technological transfers. Thus, a multilateral fund would ensure that technologies can spread to developing countries. In this way, this approach sets incentives for their participation because although being bound by the technology standards - they can gain through the diffusion of technologies in their countries which is basically financed by industrialised countries. ${ }^{17}$

Barrett emphasises that the attractiveness of this approach - based on a R\&D Protocol with complementary standards protocols - lies in the inclusion of both "push" incentives affecting the supply of R\&D, and "pull" incentives aimed at the demand for the benefits of R\&D. In contrast, the Kyoto Protocol does not consider the necessity to push $R \& D$, but is based solely on the pull incentives which only work by strong enforcement. Also, by focusing on incentives related to the funding of $R \& D$, preconditions for

\footnotetext{
16 In addition, the country's contribution should be contingent on an agreed total expenditure level and the contribution of the other countries (Barrett, 2002). The latter element ensures that the fund becomes larger when countries join the cooperation agreement and smaller when countries withdraw. In this way, an explicit incentive for participation is created and - very important - countries know their commitment costs before signing the agreement.

${ }^{17}$ An additional innovative component of this proposal is an adaptation protocol which explicitly accepts the responsibility of industrialised countries for the current situation with respect to accumulated GHG emissions. Therefore, industrialised countries need to assist developing countries in adapting to the consequences of climate change, which are very likely to be strongest in these countries.
} 
long-term technical innovation and diffusion are created. Moreover, because emission targets and time tables are not imposed, this technology-based climate regime does not require the enforcement of compliance, but does provide incentives for participation.

Note that the more countries adopt a standard, the more attractive it becomes for other countries to adopt the same standard. Hence, the more countries combat climate change, the greater are the incentives for other countries to follow suit. Therefore, there is no need for strong enforcement and monitoring. Once enough countries adopt the standards, none of them will have an incentive to defect from the agreement.

These considerations are also consistent with the recommendations derived from game theory models that study the effects of cooperation on technological innovation (Cf. Yi, 1997). If technological spillovers are limited, technological cooperation provides a club good, where benefits from cooperation are partly excludable (i.e. free riders achieve a small benefit). In this case, the equilibrium coalition structure often coincides with the grand coalition. ${ }^{18}$ By contrast, as shown in Bloch (1997), in the case of public goods, the equilibrium of the coalition game is characterised - in the most favourable cases - by a constellation of small groups of cooperating countries (climate blocs). ${ }^{19}$

Although there is no doubt that the technology-based approach also has a number of weaknesses ${ }^{20}$, it does account for some of the crucial

\footnotetext{
${ }^{18}$ Of course other assumptions are necessary, e.g. that asymmetries are negligible and that the agreement is profitable (see Yi, 1997). However, what matters in our context is the excludability of benefits from cooperation that provides incentives for all or almost all players to join the coalition.

${ }^{19}$ See also Carraro and Marchiori (2003) and the other papers in Carraro (2003).

${ }^{20}$ For example, there are problems in ensuring that the "right/best" standards are chosen and that the adoption of these standards indeed offers every participating country a benefit in excess of the cost. An additional question is who will choose the standards. A further concern is that the system gets locked in to a particular standard which would remove the incentives for further innovation.
} 
requirements needed to make an international climate regime successful: a global scale, strong elements for self-enforcement and a high degree of probability that the international system will support the approach.

However, there is a basic trade-off characterising the implementation of a technology-based climate protocol. On the one hand, technological innovation reduces emissions per unit of output by making climate-friendly technologies available and by reducing their costs. On the other hand, investments in $\mathrm{R} \& \mathrm{D}$ and technological diffusion provide a stimulus to economic growth and therefore increase GHG emissions. This is particularly true in the absence of any emission reduction targets, as proposed in Barrett $(2001,2002)$. It is therefore crucial to assess whether the adoption of a technology-based climate protocol can actually reduce GHG emissions, i.e. whether the development of new technologies and their dissemination obviates the other collateral effects of the protocol.

Note that other elements of a technology-based protocol need to be carefully verified. For example, are technological spillovers strong enough inside the coalition (the group of cooperating countries) and small enough outside the coalition (towards potential free-riders) to guarantee that all world countries are willing to adopt the protocol? In particular, will developing countries accept to sign such a protocol? In addition, technology and the skills to adopt it are not evenly distributed across the world. Are these asymmetries strong enough to prevent the emergence of a global agreement?

In order to answer these questions, and to check whether a technology-based climate protocol is actually environmentally effective, we made an applied game theory analysis of two possible scenarios: the first one is characterised by technological cooperation among the four "traditional" Kyoto countries/regions (USA, Europe, Japan, Former Soviet Union), whereas in the second one all world countries, including developing countries, cooperate on technological innovation and diffusion. For each scenario, we 
assess the profitability, stability (no free-riding incentives) and environmental effectiveness of technological cooperation.

The aim of our analysis is to verify whether cooperation on technological innovation and diffusion, without any emission reduction commitments, could actually lead to a reduction of global emissions. Were this conjecture true, we could conclude that a technology-based climate agreement would be more efficient than a climate agreement based on emission reduction targets, because the former provides excludable benefits - and thus adequate incentives for participation - while reducing the amount of GHG emissions.

Therefore, in the next section we will compare the equilibrium outcomes of a game in which countries cooperate on technological innovation and diffusion with those of a game in which countries that ratified the Kyoto Protocol comply with their emission targets from 2010 onward. This scenario, sometimes dubbed "Kyoto forever" (Cf. Buonanno, Carraro and Galeotti (2002); Manne and Richels (1999); and Chapter 8 of IPCC (2001)), will be our benchmark scenario. It is not necessarily the best one, but it is certainly not very ambitious in terms of emission abatement. If GHG emissions in a technology-based regime are larger than in the "Kyoto forever" scenario, then they are going to be larger than in other more ambitious and more important stabilisation scenarios as well.

\section{Technology-based climate regimes. An quantitative assessment}

\subsection{The modelling framework}

In the policy setting that we are going to analyse, we compare a climate regime based on emission reduction targets (like in the Kyoto Protocol), with a climate regime based on technological cooperation. For the technology-based regime, we consider two scenarios, where the group of cooperating countries is set exogenously. In the first scenario, we assume that all Annex B countries - EU, Japan, US, FSU - cooperate on 
technological innovation and diffusion, without being committed to any emission reduction targets (second regime). In the second scenario, we assume that global technological cooperation, again without any binding environmental restrictions, is implemented.

In the case of the technology-based scenarios, the first step is to verify whether the technological coalition is self-enforcing, namely profitable and stable. The definitions of profitability and stability have been derived directly from Carraro and Siniscalco (1993) (see also Eyckmans, 2001 and Weyant and Olavson, 1999 for recent applications to climate policy). We say that an agreement is weakly profitable, if the sum of the individual payoffs of the signatories is larger than the sum of their payoffs when no agreement is signed. In this case, the agreement produces a surplus (overall benefits are larger than costs), but this surplus may not benefit all signatories, i.e. some countries may gain, others may lose. By contrast, an agreement is strongly profitable, or simply profitable, if the payoff of all signatories is larger when the agreement is signed and implemented than when no agreement is signed. Hence, each single participant obtains a net benefit from the agreement. An agreement is said to be internally stable if there is no incentive to free-ride, i.e. the payoff of each signatory is larger than the payoff he/she would obtain by defecting from the group of signatories. Finally, an agreement is stable if there is no incentive to free ride and no incentive to join the group of signatories, i.e. the payoff to those countries that are not signatories is larger than the one they would receive by signing the agreement.

The analysis of the profitability and stability of our two technology-based climate agreements (the Annex B one and the global one) is based on optimisation runs obtained using the FEEM RICE model. There are currently two versions of FEEM RICE. One is based on Nordhaus and Yang's (1996) RICE 96 model, and takes explicitly into account endogenous and induced technical change. In particular, as previously 
indicated, technical change performs a twofold role: on the one hand, via increasing returns to scale, it yields endogenous growth; on the other hand, by affecting the emission/output ratio, it accounts for the adoption of cleaner and energy-saving technologies (a detailed description is in Buonanno, Carraro and Galeotti, 2002). A second version is based on Nordhaus and Boyer's (2000) RICE 99 model. This second version has a much more sophisticated representation of induced technical change, even though technical change still plays the twofold role previously described for the first version of FEEM RICE (a detailed description is in Bosetti, Carraro and Galeotti, 2004).

In the first version of FEEM RICE, six countries/regions - United States (US), Europe (EU), Japan (JPN), Former Soviet Union (FSU), China (CHN) and Rest of the World (ROW) - optimally set the intertemporal values of three strategic variables: investments, $R \& D$ expenditure and abatement rates. Given the interdependency of each country's decision, the equilibrium value of these variables is the solution to a dynamic open-loop Nash game between the six players. In the second version, there is a more detailed geographical disaggregation (8 regions) and a better representation of the production structure. Again, an open-loop Nash equilibrium is used to determine the optimal dynamic paths of all variables.

Most importantly, technical change is better modelled in the second version of FEEM RICE. In the first version, a stock of knowledge, cumulated through R\&D investments, affects both factor productivity and the emission-output ratio. Therefore, the model adopts a standard Learning by Researching approach (Cf. Goulder and Mathai, 2000). In the second version, both Learning by Doing and Learning by Researching are explicitly modelled. More precisely, R\&D investments induce the developments of environment-friendly technologies through which GHG emission abatement can be undertaken. At the same time, these abatement activities increase experience and produce learning, which enhance the effectiveness of 
environment-friendly technologies in reducing GHG emissions (see Figure 1). The emission reduction takes place through both energy-saving and fuelswitching effects. In the model, the different components of technical change have a differentiated impact on both effects. Finally, the first version of FEEM RICE also includes an estimate of international knowledge spillovers. By contrast, in the second version of FEEM RICE, international knowledge spillovers are not yet accounted for.

Figure 1. Effects of LbR and LbD on Technical Progress (TP) in FEEM RICE version 2.

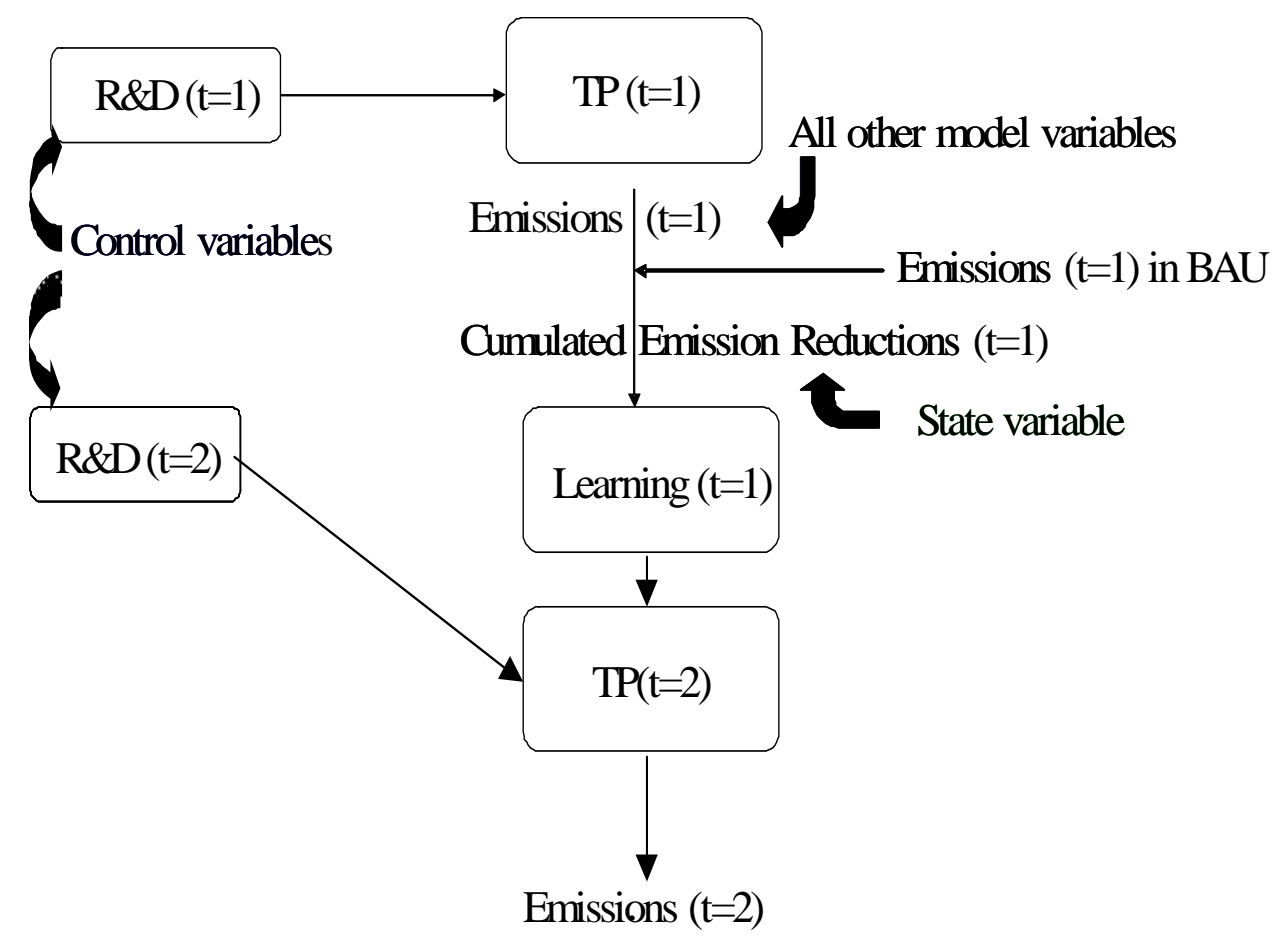

We plan to use both versions of FEEM RICE, because this enables us to test the validity of the proposal of a technology-based climate regime by using two quite different models and, above all, two very different representations of technical change. It is true that both versions are top down and in both 
versions technical change is modelled as an aggregate variable. However, our objective is normative and the scale is global (the goal is to determine the optimal intertemporal policy for all world regions); as a consequence, the tools that we plan to use are likely to be the most appropriate to achieve this goal.

In the technology-based climate regimes, countries are supposed to cooperate on technological innovation and diffusion and thus choose their R\&D expenditure in order to maximise the coalition's joint welfare function. Countries are not committed to reduce their own GHG emissions. Therefore, they implement their domestic welfare maximising abatement rate. The same holds for the third strategic variable - investment - which is again set by all countries in order to maximise domestic welfare.

By contrast, in our benchmark policy setting in which the Annex B-us countries are supposed to comply with the Kyoto Protocol, their abatement rates are set so as to achieve the Kyoto targets, whereas the US, CHN and ROW implement their domestic welfare maximising abatement rate $^{21}$. As for the other two strategic variables, they are set by all countries in a way that maximises their own domestic welfare.

In order to give technological cooperation the highest probability of being successful, we assume that climate policy is undertaken through domestic policy and measures (no flexibility mechanisms). Recent studies have shown that R\&D and flexibility mechanisms are strategic substitutes ${ }^{22}$. As a

\footnotetext{
${ }^{21}$ As already said, when deriving the results for the actual Kyoto coalition consisting of EU, JPN and FSU, we adopt the so-called "Kyoto forever" scenario which is used in most of the literature on the economic costs of climate policy. See e.g., Buonanno, Carraro and Galeotti (2002); Manne and Richels (1999); and Chapter 8 of IPCC (2001). In particular, we assume that countries which have agreed with the Marrakech negotiations commit themselves to meeting the existing Kyoto constraints from 2012 onward, given that no emission targets beyond 2012 are yet defined.

${ }^{22}$ Buonanno, Carraro and Galeotti (2002) show that an international trading system, by lowering the cost of complying with the Kyoto targets, also lowers the incentives to undertake environment-friendly $\mathrm{R} \& \mathrm{D}$. Therefore, at the equilibrium, $\mathrm{R} \& \mathrm{D}$ expenditure is
} 
consequence, countries have the largest incentive to profit from the benefits yielded by R\&D cooperation when flexibility mechanisms are not allowed for.

In the FEEM RICE model, technical change is induced by knowledge accumulation, which is the sum of past $R \& D$ expenditures. We assume that part of the technological benefits yielded by this knowledge accumulation are a global public good, whereas part of them are a club good that can be appropriated only by the $R \& D$ coalition members. Therefore, $R \& D$ cooperation is assumed to be an imperfect club good. In the first version of FEEM RICE, a parameter $\beta$ quantifies the increased share of world knowledge that can be appropriated by countries belonging to the $R \& D$ coalition. This parameter is equivalent to the "differential technological spillover" or "coalition information exchange coefficient" in the theoretical model by Carraro and Siniscalco $(1995,1997)$. The first version of FEEM RICE is thus characterised by the inclusion of two types of international spillovers and related parameterisation: spillovers - parameterised by $\varepsilon-$ which are appropriated by all countries; and spillovers - parameterised by $\beta$ - which are beneficial only to coalition members. In the second version of FEEM RICE, no estimate of international spillovers is yet included. This is the price to be paid for the more sophisticated formulation of technical change embodied in the second version of FEEM RICE.

Note that the coalition-internal spillovers $\beta$ play a crucial role in determining the stability of coalitions based on technological cooperation. Therefore, the coalition stability analysis will be performed only with the first version of the model. The second version of FEEM RICE will instead be used - under the assumption of stable cooperation - to check for the robustness of our conclusions on the effectiveness of technological cooperation in reducing global GHG emissions.

lower in all countries that benefit from emission trading. R\&D and emission trading are thus strategic substitutes. 
4.2 An applied game theory analysis of two technology-based climate regimes

In this section we proceed in a counterfactual manner. First, we assume that only the four "traditional” Kyoto regions (USA, Europe, Japan, Former Soviet Union) decide to replace environmental cooperation by technological cooperation. The other two regions - China and Rest of the World - are excluded for the moment from technological cooperation. Second, we evaluate a scenario in which a global $R \& D$ coalition forms, namely all world countries cooperate on technological innovation and diffusion. Finally, as previously explained, we compare the empirical results obtained for these two scenarios with those in the benchmark scenario, i.e. in the case of a climate coalition where the EU, JPN and FSU are committed to achieving the Kyoto targets, whereas the other countries free-ride.

Let us consider first the profitability and stability of climate agreements based on technological cooperation. Our results can be summarised as follows. Both the coalition in which Annex B countries/regions cooperate on technological innovation and diffusion and the coalition in which all world countries regions cooperate on technological innovation and diffusion are profitable and internally stable for values of $\beta \geq 0.2$. Therefore, as soon as the excludable benefits arising from technological cooperation become relevant ( $\beta \geq 0.2$, i.e. benefits for co-operators are $20 \%$ higher than benefits accruing to free-riders), all countries find it profitable to cooperate. In addition, there is no incentive to free-ride on technological cooperation. The reason lies in the availability of economic benefits (parameterised by $\beta$ ) that can be appropriated only by coalition members (this also incorporates Barrett's argument about technological standards). Let us recall that this conclusion is based on the stability analysis performed with the first version of FEEM RICE. 
The above results confirm the theoretical insights on the stability of technology-based climate regimes (i.e. on the existence of high participation incentives in these regimes). As a consequence, the crucial issue is the environmental effectiveness of a coalition in which member countries cooperate only on technological development and its diffusion. Are global emissions in the case of technology-based regimes lower than in the benchmark "Kyoto forever" scenario?

The results obtained with the first version of FEEM RICE are summarised in Tables 1 and 2. The first column shows different values of the parameter $\beta$. The second column contains the change of global emissions in the case of a technology-based regime versus global emissions in the benchmark scenario. The third column contains the change of the emission/output ratio induced by $\mathrm{R} \& \mathrm{D}$ cooperation (again with respect to the same benchmark). While the second and the third columns show the results in the first commitment period, the fourth and the fifth columns show what could happen in the medium term.

Table 1 illustrates that both global emissions and the emission/output ratio increase in the case of a technology-based protocol among Annex B countries. Note that there are no cases in which technological cooperation can induce a reduction of global emissions and/or of the emission/output ratio with respect to the "Kyoto forever" scenario. ${ }^{23}$ In addition, this empirical evidence is robust with respect to change of $\beta$ above $0.2{ }^{24}$

\footnotetext{
${ }^{23}$ At least to the extent that the first version of FEEM RICE model can adequately capture the dynamics of induced technical change.

${ }^{24}$ There is a discontinuity with respect to the value of $\beta$. As we showed in a different paper (Buchner, Carraro, Cersosimo and Marchiori, 2002) for values of $\beta$ below 0.2, external technological spillovers are too high, i.e. free riders get an excessive benefits from the R\&D investments of the coalition and thus the coalition is no longer stable. We find the same result in this paper. Therefore, we perform the sensitivity analysis only for values of $\beta$
} 
Table 1. Environmental effectiveness of a technology-based protocol among Annex B countries

\begin{tabular}{|c|c|c|c|c|}
\hline \multirow{2}{*}{} & \multicolumn{2}{|c|}{2010} & \multicolumn{2}{c|}{2050} \\
\hline $\boldsymbol{B}$ & $\begin{array}{c}\text { Percentage } \\
\text { change of } \\
\text { global emissions }\end{array}$ & $\begin{array}{c}\text { Percentage } \\
\text { change of } \\
\text { aggregate } \\
\text { emission/output } \\
\text { ratio }\end{array}$ & $\begin{array}{c}\text { Percentage } \\
\text { change of } \\
\text { global emissions }\end{array}$ & $\begin{array}{c}\text { Percentage } \\
\text { change of } \\
\text { aggregate } \\
\text { emission/output } \\
\text { ratio }\end{array}$ \\
\hline $\mathbf{0 . 2 0}$ & $+12.97 \%$ & $+12.99 \%$ & $+48.28 \%$ & $+47.99 \%$ \\
\hline $\mathbf{0 . 3 3}$ & $+12.97 \%$ & $+12.88 \%$ & $+48.87 \%$ & $+48.42 \%$ \\
\hline $\mathbf{0 . 6 6}$ & $+13.01 \%$ & $+12.68 \%$ & $+48.60 \%$ & $+47.83 \%$ \\
\hline $\mathbf{1 . 0 0}$ & $+13.07 \%$ & $+12.53 \%$ & $+48.46 \%$ & $+47.40 \%$ \\
\hline $\mathbf{1 . 5 0}$ & $+13.13 \%$ & $+12.35 \%$ & $+48.18 \%$ & $+46.88 \%$ \\
\hline
\end{tabular}

Note: $\beta$ is the differential technological spillover or coalition information exchange coefficient. Changes of emissions and of the emission/output ratio are computed with respect to the benchmark case in which the EU, JPN and FSU meet their Kyoto targets until 2050, the other countries/regions do not cooperate on emission control and no technological cooperation is implemented.

The result that technological cooperation does not seem to be environmental effective when using the formulation with international knowledge spillovers, and when only Annex B countries cooperate on technological innovation and diffusion, depends on two factors.

1) On the one hand, as a consequence of the intensified $R \& D$ efforts, production increases. This raises the emissions of the Annex B countries that cooperate on R\&D. Emissions per unit of output also increase, because the overall impact of accumulated R\&D expenditure on economic growth (the endogenous growth effect) is larger than the impact of accumulated $R \& D$ on emission abatement (the induced technical change effect).

above 0.2 (only for stable technological coalitions) and we find that our results are quite robust with respect to changes in $\beta$ above 0.2 . 
2) On the other hand, R\&D investments in Annex B countries have an impact also on the other countries (developing countries) through technological spillovers that increase output. These countries have more polluting technologies. Therefore, their increased production has a more negative effect on the environment (more emissions) than in Annex B countries, namely developing countries have a worse emission-output ratio and invest less in emission-reducing technologies. As a consequence, the average global emission-output ratio increases.

Also notice that when global emissions and the emission-output ratio increase, they increase with respect to the so called "Kyoto forever" scenario in which Annex $B_{\text {-us }}$ regions have emission targets to be achieved from 2010 onward.

The above negative conclusions on the environmental effectiveness of an international climate protocol based only on technological cooperation are even stronger when looking at the situation in 2050. Both absolute emissions and the aggregate emissions/output ratio increase by almost $50 \%$ with respect to the current situation in which only the EU, Japan and FSU are committed to comply with the Kyoto targets ${ }^{25}$.

The reason for this difference is that the effects of the increased investments in $R \& D$ can be seen more clearly in 2050 than in 2010. An important additional reason is that in the medium term technological spillovers have a strong effect on the growth rate of China and ROW (which do not participate in the technological agreement and therefore get part of the technological benefits - through the global spillovers $\varepsilon$ - at no cost ).

\footnotetext{
${ }^{25}$ The reason for this drastic increase is that we compare a situation in which the European Union, Japan and Russia are committed to strict, binding emission reduction targets (due to our use of the "Kyoto forever" assumption) to a situation in which there are no mandatory emission reduction targets.
} 
Can different conclusions be achieved if a global technology-based regime which would involve all world countries - is established? In this latter case, international spillover effects on countries outside the technology-based coalition disappear. Therefore, we could expect a much lower increase of global emissions and of the emission-output ratio.

This is indeed shown in Table 2, where however global emissions still increase with respect to the benchmark "Kyoto forever" scenario, both in the short-run and in the medium-run. However, the emission-output ratio is slightly reduced with respect to the benchmark scenario. Note that in this case results are independent of the value of $\beta$ - even though $\beta$ must be larger than 0.2 to guarantee the coalition stability - because all countries/regions are assumed to participate in the technology-based regime, i.e. they all cooperate on technological innovation and diffusion (without binding emission targets). Therefore, at the equilibrium there is no free riders an no differential technological spillovers.

Table 2. Environmental effectiveness of a global technology-based climate protocol

\begin{tabular}{|c|c|c|c|}
\hline \multicolumn{2}{|c|}{2010} & \multicolumn{2}{c|}{2050} \\
\hline $\begin{array}{c}\text { Percentage change } \\
\text { of } \\
\text { global emissions }\end{array}$ & $\begin{array}{c}\text { Percentage change } \\
\text { of aggregate } \\
\text { emission/output } \\
\text { ratio }\end{array}$ & $\begin{array}{c}\text { Percentage change } \\
\text { of } \\
\text { global emissions }\end{array}$ & $\begin{array}{c}\text { Percentage change } \\
\text { of aggregate } \\
\text { emission/output } \\
\text { ratio }\end{array}$ \\
\hline$+2.19 \%$ & $-0.27 \%$ & $+9.73 \%$ & $-3.75 \%$ \\
\hline
\end{tabular}

Again, even though global cooperation increases the economic benefits and the environmental effectiveness of the agreement, total emissions in the technology-based protocol increase with respect to total emissions in the benchmark case. The increase of emissions is smaller when all world regions cooperate to develop and diffuse climate-friendly technologies than 
in the case in which developing countries free ride. However, the hypothesis that a policy which fosters technological cooperation can also induce less GHG emissions is not supported by our results. ${ }^{26}$

The tentative conclusion is that technological cooperation cannot replace environmental cooperation. Within the limits of the first version of FEEM RICE, our game theory analysis suggests that technological cooperation increases $\mathrm{R} \& \mathrm{D}$, growth and welfare, but also emissions. As a consequence, some environmental policy measures, to be coupled with technological cooperation, seem to be necessary to achieve an environmentally satisfactory regime. If appropriately designed, these environmental policy measures could also provide additional incentives to invest in climatefriendly technological change $e^{27}$.

To further check the robustness of the above conclusions, let us use the second version of FEEM RICE, where technical change is better endogenised. In this second version, there are no international technological spillovers. Therefore, we cannot check the stability of the coalition with respect to $\beta$. We thus simply assume that all world countries/regions choose to cooperate on technological innovation and diffusion. We then assess the amount of resulting emissions and we compare it with global emissions in the benchmark scenario.

\footnotetext{
${ }^{26}$ Note that results in the scenario in which all region cooperate on technological innovation and diffusion are consistent with the so called "environmental Kuznets curve" hypothesis. This was not the case for results shown in Table 1. However, let us also stress that there is no conclusive evidence on the existence of an "environmental Kuznets curve" for GHG emissions. Recent studies find curves of all shapes (see e.g. Kelly, 2003; or Bartz and Kelly, 2004). And Holtz-Eakin and Selden (1995) find that the pace of economic development does not significantly alter the flow of $\mathrm{CO} 2$ emissions, thus yielding an "environmental Kuznets curve" that never turns down.

${ }^{27}$ Some results obtained in Buchner, Carraro, Cersosimo and Marchiori (2002) provide support to this conclusion. Indeed, we found that total emissions when all or part of the Annex B countries adopt technological cooperation and environmental policy measures to achieve the Kyoto targets, are smaller than total emissions when international cooperation concerns only technological innovation and diffusion. Moreover, with both technological and climate cooperation, global emissions are smaller than the global Kyoto target itself.
} 
With the new model, results are more in favour of a technology-based climate regime. Figure 2 shows the dynamic behaviour of total emissions. Note that, in the presence of climate-friendly technological cooperation without emission targets, world carbon emissions decrease with respect to emissions in the "Kyoto forever" scenario.

Figure 2. The dynamics of carbon emissions in the BAU, in the "Kyoto Forever" scenario and in the presence of technological cooperation without emission targets.

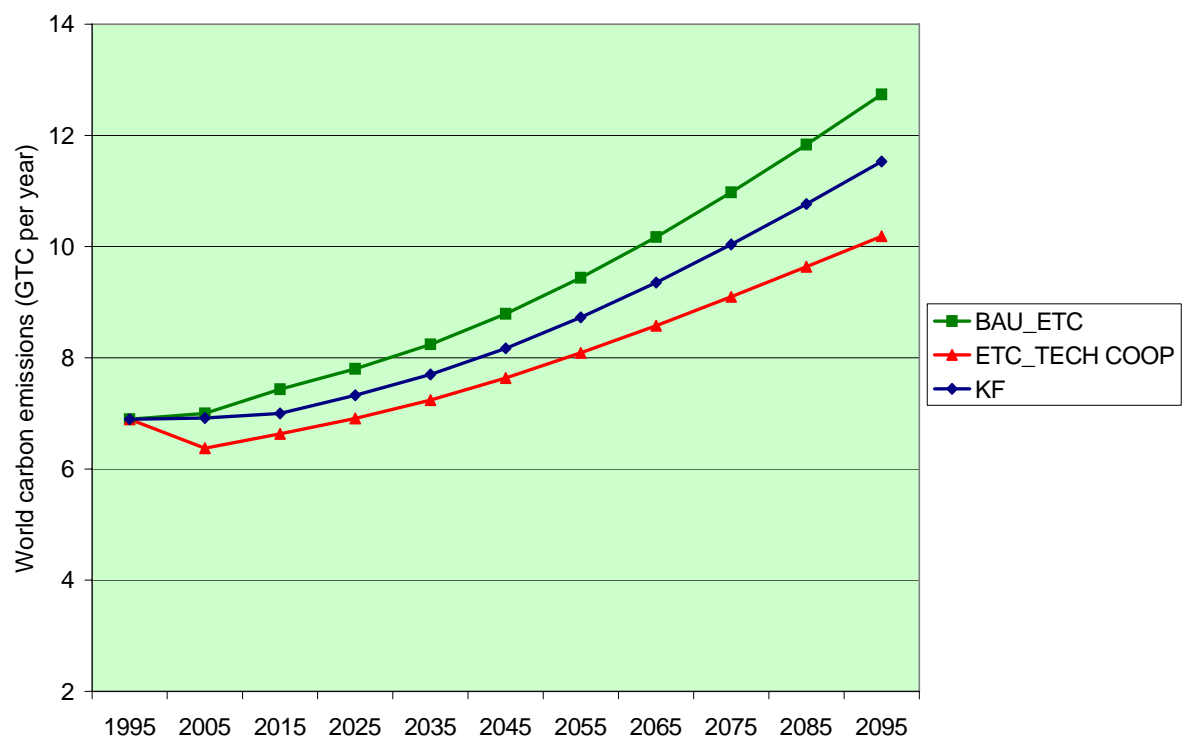

Therefore, with this new model, a technology-based climate regimes seems to be more environmental effective than an emission-based climate regime. However, the comparison is made with the "Kyoto forever" scenario, whose environmental effectiveness is reduced by the absence of mandatory targets for the US, China and other big emitters. This comparison would be useful only if, as in the case of the first version of FEEM RICE, emission in the presence of technological cooperation were larger than in the "Kyoto forever” scenario.

Let us therefore consider a different emission-based scenario. We assume that all countries are committed to achieve a 550 ppm stabilisation goal, and 
that they can decide to achieve it either with or without technological cooperation. Figure 3 shows the dynamics of carbon emissions when technological cooperation is implemented without an emission target, when the $550 \mathrm{ppm}$ stabilisation target is achieved without technological cooperation, and when technological cooperation is also implemented.

Figure 3. The dynamics of carbon emissions in the technology-based scenario, in the $550 \mathrm{ppm}$ stabilisation scenario without technological cooperation and in the 550 ppm stabilisation scenario with technological cooperation.

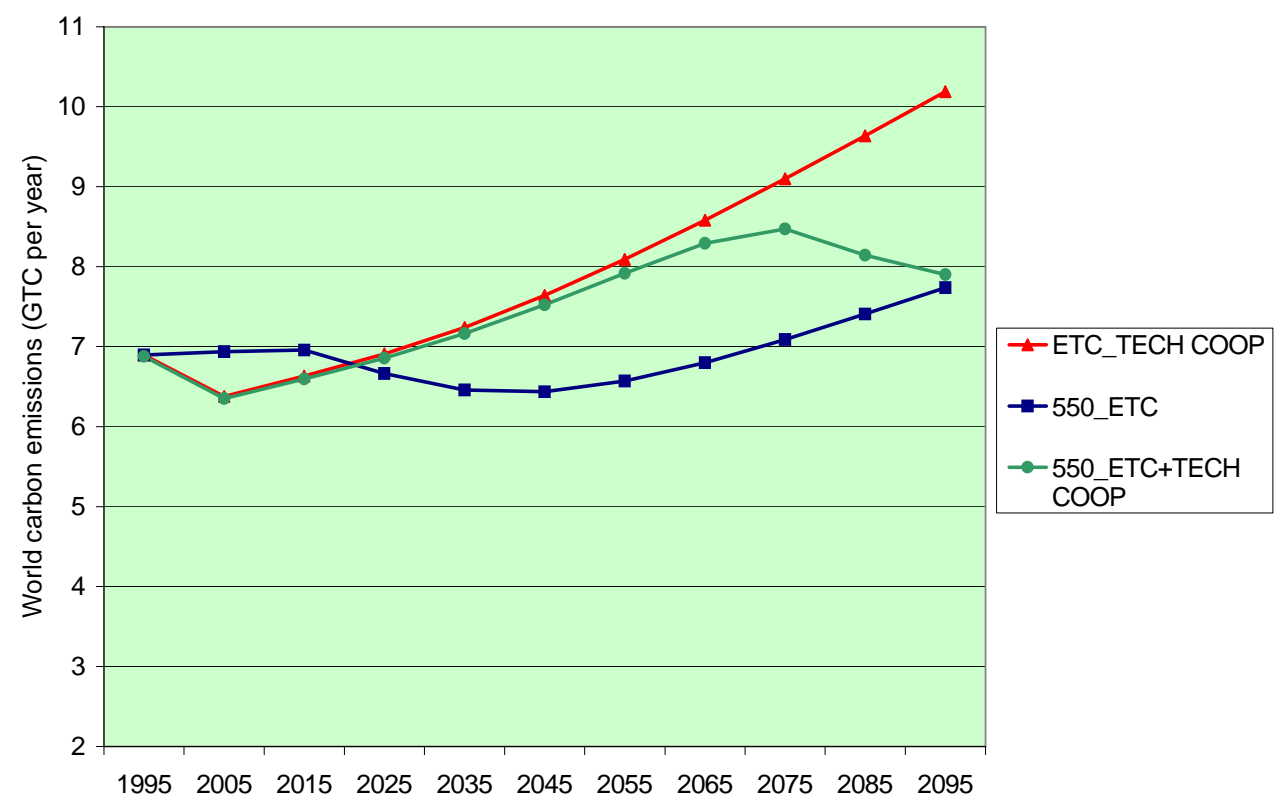

There are a few interesting remarks that can be derived by looking at Figure 3. First, technological cooperation alone, without emission targets, can stabilise concentrations at a level very close to $550 \mathrm{ppm}$. Only in the long run the line describing emissions in the case of technological cooperation without an emission target diverges from the line describing emissions when the 550 ppm stabilisation target is optimally achieved without technological cooperation. Therefore, in the new version of FEEM RICE, technological 
cooperation yields the kind of scenarios outlined in Hanson et al (2004). ${ }^{28}$ That is, cooperative technology development (independent of climate policies) drives the market in such a way as to increase both GDP and reduce GHG intensities. As a consequence, if countries cooperate on technological innovation and diffusion, 550 ppmv may become the new reference case; and the capacity of the economy may be sufficiently strengthened such that, when the time arrives and climate issues inevitably emerge as a critical policy driver, there will be significant shift in commitment and resources to achieve an even smaller level of emissions (see also Velte et al., 2004 for this kind of scenario).

Nonetheless, in the presence of technological cooperation, emissions are larger than in the two cases in which an emission target is introduced. Therefore, a second remark is as follows. The presence of an emission target lowers emissions more than what technological cooperation alone would do. Is it therefore optimal to have both technological cooperation and a stringent emission target? Figure 3 provides an ambiguous answer. Both with and without technological cooperation it is possible to achieve the stabilisation target. However, the timing of policy is different. With technological cooperation, emissions are smaller at the beginning of the optimisation period and then become larger. The reason is that it is profitable for countries to invest in $R \& D$ and to abate emissions early rather than late, in order to exploit the benefits provided by $R \& D$ investments and the related learning process. In other words, countries find it optimal to accelerate the movement along the technology learning curves. This is shown in Figure 4, where $\mathrm{R} \& \mathrm{D}$ investments are larger in the presence of technological cooperation than without it.

In particular, in the first commitment periods, if countries cooperate on technological innovation and diffusion, they find it optimal to increase their R\&D investments, which then display their beneficial impacts in the

\footnotetext{
${ }^{28}$ We are grateful to one of the referees for this reference.
} 
subsequent periods. Among these positive impacts there are those on economic growth, which however increase emissions, as Figure 3 shows. Therefore, we find again the effect that was dominant in the case of the first version of FEEM RICE, namely that larger initial R\&D investments stimulate economic growth and therefore have negative effects on emissions in the long-run. This effect is however milder in the second version of FEEM RICE than in the first version, because of the stronger and more diffuse effects of technical change on carbon intensity and energy efficiency.

It may be interesting to observe what happens when a more stringent abatement target is imposed. Figure 5, where the dynamics of carbon emissions in the presence of a 450 stabilisation target is also shown, suggests that technological cooperation may be redundant if countries must comply with a more stringent stabilisation goal.

Figure 4. The dynamics of $R \& D$ investments in the technology-based scenario, in the $550 \mathrm{ppm}$ stabilisation scenario without technological cooperation and in the 550 ppm stabilisation scenario with technological cooperation.

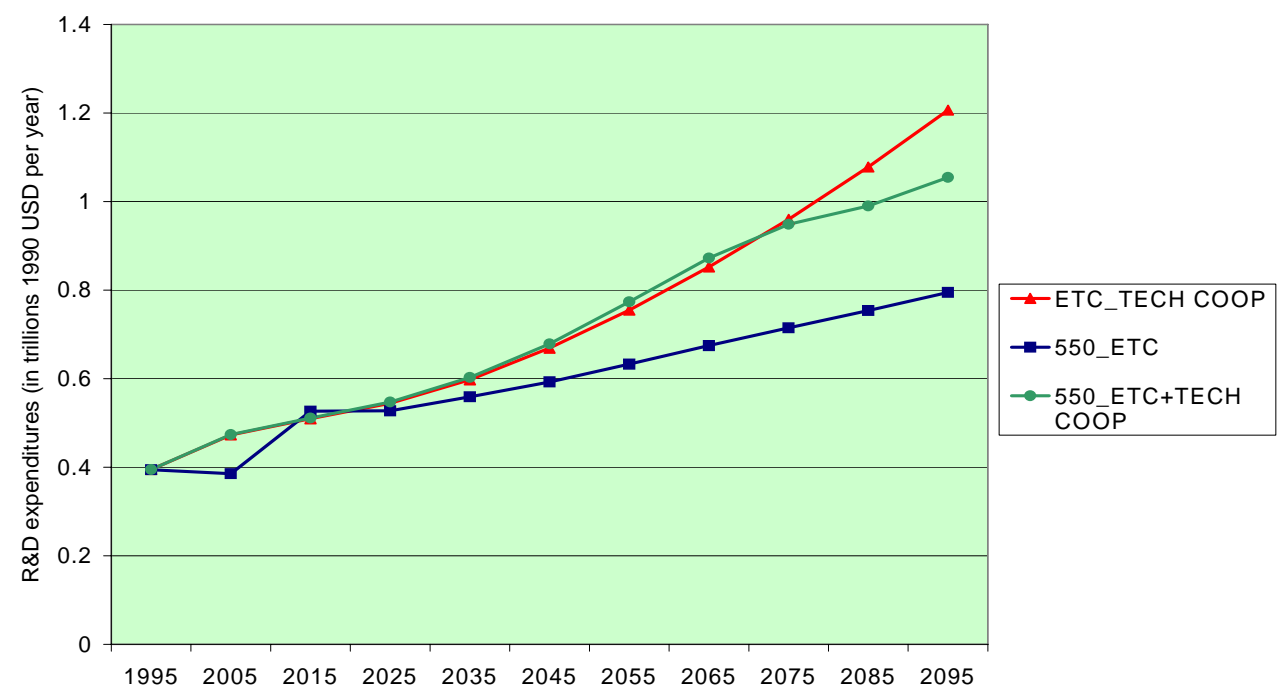


The line describing the optimal emission path with technological cooperation almost coincides with the one in which technological cooperation is not carried out. Therefore, in the presence of a very stringent emission target, the amount of $R \& D$ investments that a single country finds it optimal to undertake unilaterally almost coincides with the amount that it would undertake in the presence of technological cooperation, i.e. a joint decision about optimal investments in $R \& D$. There is still a difference in the first commitment periods, where more $R \& D$ investments are undertaken in the case of technological cooperation.

Figure 5. The dynamics of carbon emissions in the technology-based scenario, in the 550 and $450 \mathrm{ppm}$ stabilisation scenarios without technological cooperation and in the 550 and 450 ppm stabilisation scenarios with technological cooperation.

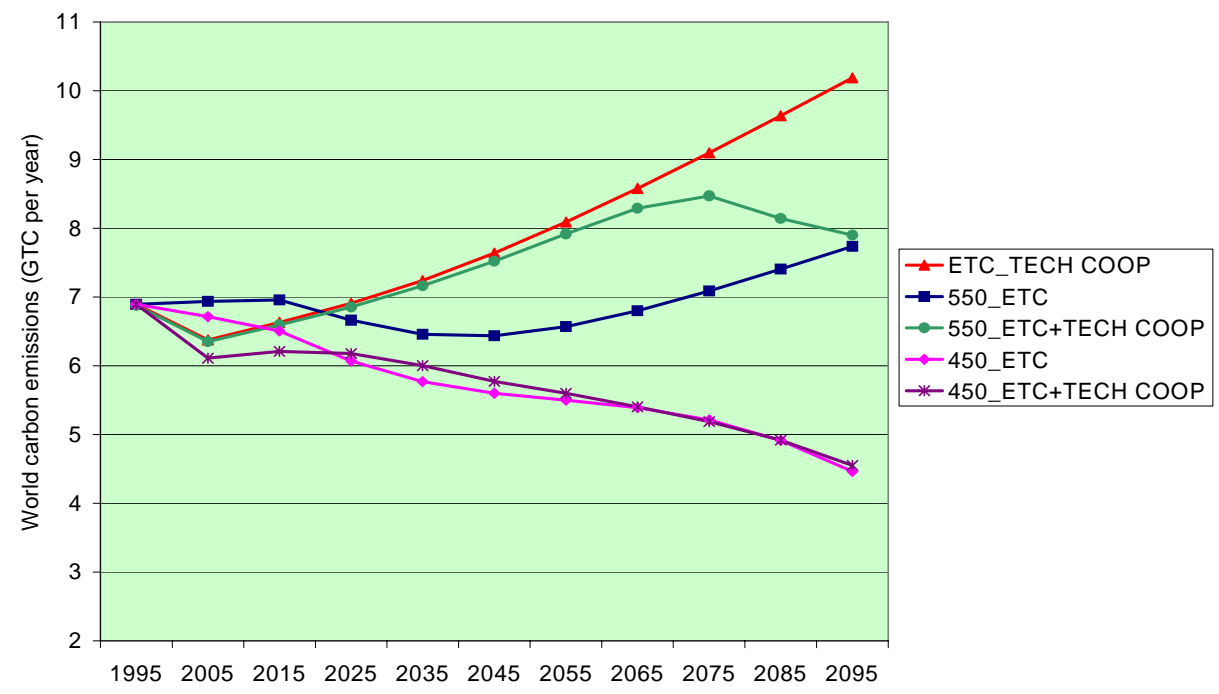

\section{Conclusions}

The analysis of this paper has been motivated by the increasing number of bilateral deals on technological cooperation that have emerged following the US withdrawal from the Kyoto Protocol. In addition, and independently of this flow of initiatives on technological cooperation, the proposal of a technology-based climate protocol has been debated from a theoretical 
perspective and its properties in terms of participation incentives have been highlighted by several authors (e.g. Barrett, 2001, 2002).

As a consequence, the main objective of this paper was to verify, using an applied game theory approach, whether a climate regime based on cooperation on technological innovation and diffusion, without any binding abatement commitments, could be self-enforcing and yield lower total carbon emissions than the standard - not very environmentally ambitious “Kyoto forever” regime. Were this conjecture true, a technology-based climate agreement could replace agreements focused on emission abatement targets, because it would provide both stronger incentives to participate and a better performance in terms of environmental effectiveness.

The scenarios that have been analysed in this paper partly support the above conjecture. A technology- based regime is more stable than an emissionbased regime, i.e. more countries are likely to participate in the climate regime. In addition, technological cooperation without emission abatement commitments increases economic growth. However, this strategy is unlikely to lower global GHG emissions, i.e. a technology-based protocol does not seem to be environmentally effective. This conclusion is clearly supported by our analysis with the first version of FEEM RICE, but is less cogent when using the second version of FEEM RICE. In this latter case, technical change is more effective in reducing carbon and energy intensity. Therefore, technological cooperation can do better than a "Kyoto forever" regime in reducing global carbon emissions. However, technological cooperation becomes less and less important as the stringency of the stabilisation goal increases. The reason is that stringent stabilisation goals induce large $R \& D$ investments even in the absence of technological cooperation.

Of course, the conclusions of this study need to be tested using other models and other specifications of technical change. This would provide additional evidence on the properties of a technology-based climate protocol and 
would enable us to draw sounder conclusions. At the same time, the conclusion of this study should not be taken as a rejection of a technologybased protocol. Its solid theoretical properties, the positive signs expressed by the industry towards a technology-based regime and the increased amount of bilateral deals signed among different countries around the world suggest that technological cooperation would be part of a successful strategy to control climate change. Technological cooperation should be considered as an element of a more comprehensive policy strategy through which emission reductions are actually achieved at the global level - possibly in a cost-effective way and with the contribution of most of the world's countries.

\section{REFERENCES}

Aldy, J.E., Barrett, S. and R. Stavins (2003), "Thirteen Plus One: A Comparison of Global Climate Policy Architectures.” Climate Policy, 3(4), 373-397.

Aldy, J.E., Ashton, J., Baron, R., Bodansky, D., Charnovitz, S., Diringer, E., Heller, T.C., Pershing, J., Shukla, P.R., Tubiana, L., Tudela, F. and Wang, X. (2003). Beyond Kyoto: Advancing the International Effort Against Climate Change, Pew Center on Global Climate Change.

Barrett, S. (2001), “Towards a Better Climate Treaty”, Policy Matters 0129, Washington, DC: AEI-Brookings Joint Center for Regulatory Studies.

Barrett, S. (2002), Environment and Statecraft. Oxford: Oxford University Press.

Barrett, S. and R. N. Stavins (2004), "Increasing Participation and Compliance in International Climate Change Agreements", International Environmental Agreements: Politics, Law and Economics, forthcoming.

Bartz, S. and D. Kelly (2004), “Economic Growth and the Environment: Theory and Facts”, Working Paper, University of Miami.

Baumert, K., Blanchard, O., Llosa, S. and Perkaus, J. (eds.) (2002). Building on the Kyoto Protocol: Options for Protecting the Climate, World Resource Institute (WRI). 
Benedick, R.E. (2001), "Striking a New Deal on Climate Change”, Issue in Science and Technology. Fall: 71-76.

Bloch, F. (1997), "Non-Cooperative Models of Coalition Formation in Games with Spillovers”, in C. Carraro and D. Siniscalco, eds., New Directions in the Economic Theory of the Environment, Cambridge University Press, Cambridge, ch. 10, 311-352.

Bosetti, V., Carraro, C. and M. Galeotti (2004), "The Dynamics of Carbon and Energy Intensity in a Model of Endogenous Technical Change”, FEEM , Milan.

Buchner, B. and C. Carraro (2003), "China and the Evolution of the Present Climate Regime”, FEEM Nota di Lavoro 103.03, Milan.

Buchner, B. and C. Carraro (2004), "Regional and Sub-Global Climate Regimes”, FEEM Working Paper, Milan.

Buchner, B., C. Carraro, I. Cersosimo and C. Marchiori (2002), "Back to Kyoto? US Participation and the Linkage between R\&D and Climate Cooperation”, CEPR Discussion Paper 3299 and CESifo Working Paper No. 688 (8). Forthcoming in A. Haurie and L. Viguier, eds., Coupling Climate and Economic Dynamics, Kluwer Academic Publisher.

Buonanno, P., Carraro, C. and M. Galeotti (2002), "Endogenous Induced Technological Change and the Costs of Kyoto", Resource and Energy Economics, 524, 11-35.

Carraro, C., ed., (2003), The Endogenous Formation of Economic Coalitions, Edward Elgar, Cheltenham.

Carraro, C. and M. Galeotti (2002), "The Future Evolution of the Kyoto Protocol. Costs, Benefits, Incentives to Ratification and New International Regimes”, in C. Carraro and C. Egenhofer, eds., Firms, Governments and Climate Policy: Incentive-Based Policies for LongTerm Climate Change, Edward Elgar, Cheltenham, 2002.

Carraro, C. and C. Marchiori (2003), “Stable Coalitions”, in C. Carraro, ed., The Endogenous Formation of Economic Coalitions, Edward Elgar, Cheltenham.

Carraro, C. and D. Siniscalco (1993), "Strategies for the International Protection of the Environment”, Journal of Public Economics, 52, 309-328.

Carraro, C. and D. Siniscalco (1995), "Policy Coordination for Sustainability: Commitments, Transfers, and Linked Negotiations”, in I. Goldin and A. Winters, eds., The Economics of Sustainable Development, Cambridge University Press, Cambridge.

Carraro, C. and D. Siniscalco (1997), "R\&D Cooperation and the Stability of International Environmental Agreements”, in C. Carraro, ed., International Environmental Agreements: Strategic Policy Issues, E. Elgar, Cheltenham. 
CNRS/LEPII-EPE, RIVM/MNP, ICCS-NTUA and CES-KUL (2003). Greenhouse Gas Reduction Pathways in the UNFCCC Process Up To 2025; Policymakers Summary, Study prepared for DG Environment, downloadable

http://europe.eu.int/comm/environment/climat/studies.htm

Cooper, R. (1998), “Toward a Real Global Warming Treaty.”, Foreign Affairs, 77(2), 66-79.

CO2e.com, Australia, US sign rebel pact on carbon: Australasian Business Intelligence, July $7^{\text {th }}$, 2002. Online at www.co2e.com

CO2e.com, Japan, U.S. agree on 15 steps on global warming: Jiji Press, April 5th, 2002. Online at www.co2e.com

De Moor, A.P.G., Berk, M.M., den Elzen, M.G.J. and D.P. van Vuuren (2002), "Evaluating the Bush Climate Change Initiative", RIVM rapport 728001019/2002

Edmonds, J. (2001), “Atmospheric Stabilization: Technology Needs, Opportunities, and Timing”, mimeo, Batelle Labs. Washington, DC.

Edmonds, J., J.M. Roop and M.J. Scott. (2000), "Technology and the Economics of Climate Change Policy”, Prepared for the Pew Center on Global Climate Change, Batelle, Washington, DC.

EIA (Energy Information Administration), 2003, Japan: Environmental Issues, Country Analysis Briefs, Online at http://www.eia.doe.gov/

Eyckmans, J. (2001), “On the Farsighted Stability of the Kyoto Protocol, Some Simulation Results”, ETE Working Paper No. 2001-03, Katholieke Universiteit Leuven, University of Leuven.

Flannery, B.P. (2001), “Alternative Climate Proposals: An Efforts-based Approach”, Exxon Mobil Cooperation. Presentation prepared for the International Conference on Climate Policy - Do We Need A New Approach?, Venice, Sept. 6-8, 2001.

Goulder, L.H. (2002), "U.S. Climate Change Policy: The Bush Administration's Plan and Beyond”, Policy Brief, Stanford Institute for Economic Policy Research.

Goulder, L.H. and K. Mathai (2000), "Optimal CO2 Abatement in the Presence of Induced Technological Change", Journal of Environmental Economics and Management, 39, 1-38.

Hanson, D. A., I. Mintzer, J.A. Laitner, and L. J. Amber (2004), “Engines of Growth: Energy Challenges, Opportunities, and Uncertainties in the 21st Century”, Argonne, IL: Argonne National Laboratory.

Holtz-Eakin, D. and T.M. Selden (1995), "Stoking the Fires? CO2 Emissions and Economic Growth”, Journal of Public Economics, 57, 85-101.

IPCC (2001), Third Assessment Report. Cambridge, University Press. 
Jacoby, H.D. (1998), “The Uses and Misuses of Technology Development as a Component of Climate Policy”, MIT Report No. 43, MIT Joint Program on the Science and Policy of Climate Change.

Jiji Press, Japan to push gas emission cut in Asia, August 1st, 2002. Online at www.natsource.com

Kelly, D. L. (2003), "On Environmental Kuznets Curves Arising From Stock Externalities", Journal of Economic Daynamics and Control, Elsevier, vol. 27(8), pages 1367-1390.

Kopp, R., R. Morgenstern, W. Pizer and M. Toman. (1999), “A Proposal for Credible Early Action in U.S. Climate Policy”, Washington D.C.: RFF.

Manne, A. and R. Richels (1999), "The Kyoto Protocol: A Cost-Effective Strategy for Meeting Environmental Objectives?” in J. Weyant, ed., The Cost of the Kyoto Protocol: A Multi-Model Evaluation. Special Issue of the Energy Journal.

McKibbin, W.J. and P.J. Wilcoxen (1997), “A Better Way to Slow Global Climate Change”, Brookings Policy Brief No. 17, Washington, D.C.: Brookings Institution..

McKibbin, W.J. (2000), "Moving Beyond Kyoto”, Brookings Policy Brief No. 66, Washington, D.C.: Brookings Institution.

News.com.au, Aus, US launch climate plan, July $2^{\text {nd }}$, 2002. Online at www.news.com.au

Nordhaus, W. D. (2001), “After Kyoto: Alternative Mechanisms to Control Global Warming”, paper presented at the 20th Anniversary Meeting of the International Energy Workshop, IIASA, Laxenburg, June 21, 2001.

Nordhaus, W.D. and J. Boyer (2000), Warming the World, Cambridge: MIT Press.

Nordhaus, W.D. and Z. Yang (1996), "A Regional Dynamic GeneralEquilibrium Model of Alternative Climate-Change Strategies", American Economic Review, 4, 741-765.

OECD/IEA (2002). Beyond Kyoto: Energy Dynamics and Climate Stabilisation. Paris.

Parry, I.W.H., W.A. Pizer and C. Fischer (2002), "How Large Are the Welfare Gains from Technological Innovation Induced by Environmental Policies?”, RFF Discussion Paper 02-57, Washington, D.C.

Pravda, January 17th, 2003: Russia, U.S. to Resume Climate Change Dialogue, Online at http://english.pravda.ru/society/2003/01/17/42205.html

Schelling, T. (2002), "What Makes Greenhouse Sense?”, Foreign Affairs, 81(3). 
Schmalensee, R. (1998) Greenhouse Policy Architecture and Institutions. In W.D. Nordhaus, ed., Economics and Policy Issues in Climate Change, pp.137-158. Washington, D.C.: Resources for the Future.

The Daily Yomiuri, Japan to seek Asian CO2 credits. August 26th, 2002. Online at www.yomiuri.co.jp

Tol, R., Lise, W. and B. van der Zwaan (2000), “Technology Diffusion and the Stability of Climate Coalitions”, FEEM Working Paper 20.2000, Milan.

Velte, D., J.P., Lopez de Araguas, O. Nielsen, and W. Jörß (2004), “The EurEnDel Scenarios: Europe's Energy System by 2030”, Berlin, Germany: EurEnDel.

Victor, D.G. (2001), “Climate of Doubt”, The Sciences, Spring 2001.

Viguier, L. (2002), “The U.S. Climate Change Policy: A Preliminary Evaluation”, CFE Policy Brief No. 1.

Weyant, J.P. and T. Olavson (1999), "Issues in Modelling Induced Technological Change in Energy, Environmental, and Climate Policy”, Environmental Modelling and Assessment, 4, 67-85.

White House (2002), Executive Summary of Global Climate Change Policy Book.

Yi, S. (1997), "Stable Coalition Structures with Externalities", Games and Economic Behaviour, 20, 201-23. 